\title{
Cerebrospinal fluid biomarkers in the differential diagnosis of Alzheimer's disease from other cortical dementias
}

Leonardo Cruz de Souza (MD) ${ }^{\mathrm{a}, \mathrm{b}} *$, Foudil Lamari $(\mathrm{MD}, \mathrm{PhD})^{\mathrm{c}} *$, Serge Belliard $(\mathrm{MD}, \mathrm{PhD})$

${ }^{\mathrm{d}}$, Claude Jardel (MD, PhD) ${ }^{\mathrm{c}}$, Caroline Houillier (MD) ${ }^{\mathrm{b}}$, Raphael De Paz (MD) ${ }^{\mathrm{b}}$, Bruno

Dubois $(\mathrm{MD}, \mathrm{PhD})^{\mathrm{a}, \mathrm{b}}$ and Marie Sarazin $(\mathrm{MD}, \mathrm{PhD})^{\mathrm{a}, \mathrm{b}}$.

${ }^{a}$ CRICM, UPMC Univ Paris 06, Pitié-Salpêtrière Hospital, 47-83 bd de l'Hôpital, 75013

Paris, France

${ }^{\mathrm{b}}$ Alzheimer Institute ; Research and Resource Memory Centre; Centre de Référence de

Démences Rares, Pitié-Salpêtrière Hospital, 47-83 boulevard de l'Hôpital, 75013 Paris,

France

${ }^{c}$ Department of Metabolic Biochemistry, Pitié-Salpêtrière Hospital, Paris, France.

d Department of Neurology, Centre Hospitalier Régional et Universitaire de Rennes, France.

* These authors contributed equally to this work.

Correspondence: Dr. Marie Sarazin

Fédération des maladies du Système Nerveux, Research and Resource Memory Centre, Pavillon Paul Castaigne, Hôpital de la Salpêtrière, 47

Bd de l'Hôpital, 75013 Paris

Email : $\underline{\text { marie.sarazin@psl.aphp.fr }}$

Tel: 00331421619 86; fax: 0033142162739 
Word count for the paper: 3360

Word count for the abstract: $\mathbf{2 4 7}$

Character count for the title: $\mathbf{1 0 0}$

Number of tables: 03

Number of figures: 02

Supplemental material: 01 (Table 4)

The statistical analyses were conducted by Foudil Lamari and Leonardo C. de Souza.

\section{Key-Words:}

Alzheimer's disease

Frontotemporal dementia

Semantic dementia

Posterior Cortical Atrophy

Biomarkers 


\section{ABSTRACT}

Background: Considering that most of semantic dementia (SD) and frontotemporal dementia (FTD) patients show no postmortem Alzheimer's disease (AD) pathology, cerebrospinal fluid (CSF) biomarkers may be of value for distinguishing these patients from those with AD. Additionally, biomarkers may be useful for identifying patients with atypical phenotypic presentations of $\mathrm{AD}$, such as posterior cortical atrophy (PCA) and primary progressive non-

\section{fluent or logopenic aphasia (PNFLA).}

Methods: We investigated CSF biomarkers (beta-amyloid 1-42 $\left(\mathrm{A} \beta_{42}\right)$, total tau (T-tau), and phosphorylated tau [P-tau]) in 164 patients with AD ( $n=60)$, PCA $(n=15)$, behavioral variant FTD ( $n=27)$, SD ( $n=19),($ PNFLA) $(n=26)$ and functional cognitive disorders (FCD, $n=17)$.

We then examined the diagnostic value of these CSF biomarkers in distinguishing the patients from those with AD.

Results: The P-Tau/A $\beta_{42}$ ratio was found to be the best biomarker for discriminating AD from FTD and SD, with a sensitivity of $91.7 \%$ and $98.3 \%$, respectively, and a specificity of $92.6 \%$ and $84.2 \%$, respectively. As expected, biomarkers were less effective in differentiating AD from PNFLA and PCA, as significant proportions of PCA and PNFLA patients $(60 \%$ and $61.5 \%$, respectively) had concurrent alterations of both T-tau/A $\beta_{42}$ and P-Tau/A $\beta_{42}$ ratios. None of the FCD patients had a typical AD CSF profile or abnormal T-tau/A $\beta_{42}$ or P$\mathrm{Tau} / \mathrm{A} \beta_{42}$ ratios.

Conclusion: The P-Tau/A $\beta_{42}$ ratio is a useful tool to discriminate $\mathrm{AD}$ from both FTD and SD, which are known to involve pathological processes distinct from AD. Biomarkers could be useful for identifying patients with an atypical AD phenotype that includes PNFLA and PCA. 


\section{INTRODUCTION}

With the prospect of disease-modifying drugs that will target the physiopathological process of Alzheimer's disease (AD), it is crucial to improve the efficacy of the differential diagnosis between $\mathrm{AD}$ and other cortical dementia. The determination of cerebrospinal fluid (CSF) biomarker profiles of cortical dementias may ameliorate the distinction between AD and newly characterized non-AD dementias, such as frontotemporal dementia (FTD) and semantic dementia (SD). In addition, it may identify potential patients with atypical phenotypic presentation of $\mathrm{AD}$, such as posterior cortical atrophy (PCA) and primary progressive aphasia (PPA), who may be candidates for emerging therapies.

The CSF biomarkers total tau (T-tau), phosphorylated tau (P-tau) and beta-amyloid peptide 1-42 (A $\beta 42)$ can distinguish controls from $\mathrm{AD}$ subjects [1, 2], even in early stages of the disease [3-8]. The accuracy of CSF biomarkers in the differential diagnosis between AD and other cortical dementias, however, is not well understood. Previous studies have primarily focused on the interest of biomarkers to discriminate $\mathrm{AD}$ from frontal variants of frontotemporal lobar degenerations (FTLD), which are defined by behavioral changes. These studies have found that CSF biomarkers are useful in discriminating AD from FTD [9-17], and one study [11] demonstrated the high sensitivity and specificity of biomarkers in distinguishing AD from proven FTD (confirmation via autopsy and genetics).

Besides these data, some important questions remain unresolved. First, the ability of CSF biomarkers to distinguish AD from non-behavioral variants of FTLDs, such as SD, remains to be studied. The diagnosis of SD can be difficult and is a common cause of the misdiagnosis of $\mathrm{AD}$ [18]. While neuropathological studies have reported a lack of AD lesions in most SD patients [18-21], one study (which included a small sample of patients) reported that CSF biomarkers in SD subjects showed a similar CSF profile to that of AD patients [14], 
showing an unexpected low power of biomarkers to discriminate between these two distinct pathologies.

The second unsolved question is the ability of CSF biomarkers to identify AD pathology in atypical focal cortical presentations of AD, such as PCA and logopenic PPA [18, 19, 22]. Different from AD, PCA and logopenic PPA are characterized by specific clinical presentations (e.g., visual-spatial difficulties in PCA), with relative respect to episodic memory and focal atrophy. The most frequent underlying pathology found in autopsy studies, however, is $\mathrm{AD}$ [18]. Thus, these conditions have been coined focal cortical presentations of AD [18]. Biomarkers may be able to identify the biological mechanisms of PCA and PPA and may also be useful for selecting patients who would benefit from new disease-modifying therapies.

The main objective of this study was to analyze the usefulness of CSF biomarkers for discriminating AD from FTD, SD, PCA and primary progressive non-fluent or logopenic aphasia (PNFLA). We analyzed individual data to identify how CSF biomarkers can be included in the differential diagnosis of $\mathrm{AD}$ in clinical practice.

\section{METHODS}

The study included 164 patients hospitalized between May, 2007, and July, 2009, at the Center of Cognitive and Behavioral Diseases, Pitié-Salpêtrière Hospital, Paris, France (n=160 patients) or at the University Hospital of Rennes (France) ( $\mathrm{n}=4$ patients).

All patients were evaluated by neurologists experienced in the care of patients with neurodegenerative diseases. All patients underwent a neuropsychological examination that included the Mini Mental State Exam [23], free and cued selective reminding test (FCSRT) [24] for verbal episodic memory, Frontal Assessment Battery [25] for executive functions, digit spans for working memory, Verbal Fluency (letter S and category: fruit in 2 minutes) 
[26], gestual praxis and visuoconstructive function by copying the Rey figure or MMSE pentagons. When dementia other than that observed in AD was clinically suspected, an additional specific neuropsychological battery was administered to increase the specificity of the clinical diagnosis using tests to assess orbitofrontal function for FTD, semantic memory for SD, and Balint's syndrome and Gerstman syndrome for PCA.

All patients underwent standardized serum tests (for B12, thyroid functioning, sedimentation rate, and so on) to investigate other causes of non-neurodegenerative dementia in younger patients. All subjects underwent structural magnetic resonance imaging (MRI) or computed tomography (CT) when MRI was not possible. Brain perfusion (99m)Tc-ECD SPECT was proposed for most of the patients $(n=131 / 164)$, especially when a non-AD dementia diagnosis was suspected.

Patients were excluded from the study if they presented any of the following: 1) systemic illnesses that could interfere with cognitive functioning; 2) extrapyramidal signs or neurological history suggestive of Parkinson's disease with dementia, progressive supranuclear palsy, corticobasal degeneration or dementia with Lewy bodies; 3) vascular lesions on MRI or neurological history suggestive of vascular dementia; or 4) motor-neuron disease.

Patients were divided into the following six distinct diagnostic groups: (1) probable AD according to NINCDS-ADRDA criteria [27]; (2) behavioral variant of FTLD according to the latest revised criteria [28, 29]; (3) SD, defined as a primary progressive aphasia and characterized by fluent speech, marked anomia, impaired word comprehension, deficits in non-verbal semantic association tasks and possible prosopagnosia [28, 30, 31]; (4) PNFLA, characterized by the presence of predominant effortful speech output with word finding difficulty, possible phonological and/or syntactic errors, relative sparing of single-word comprehension and possible deficits in sentence repetition [20, 32, 33]; 5) PCA, defined by 
initial presentation of progressive visual or visuospatial impairment in the absence of ophthalmologic impairment with evidence of complex visual and/or visuospatial disorder on examination and a relatively preserved episodic memory [34, 35]; and 6) functional cognitive disorders (FCD), defined as a psychiatric diagnosis, such as depression, bipolar disorders or generalized anxiety disorders.

Most of patients were on symptomatic treatment (mainly anticholinesterasic medications and/or serotonin-specific reuptake inhibitor).

To improve diagnostic accuracy, all patients were clinically followed for at least 18 months (at least 6 months before lumbar puncture and at least 12 months after lumbar puncture). The probable clinical diagnosis was established according to the above clinical criteria using a consensus mechanism blind to CSF biomarkers values. The clinical diagnosis was then coupled with laboratory data for CSF biomarkers to establish the sensitivity and specificity for each CSF biomarker to distinguish AD patients from other groups of patients.

\section{Sample collection and biochemical measurements}

CSF samples obtained by lumbar puncture were centrifuged for 10 minutes at $1500 \mathrm{rpm}$ at $4^{\circ} \mathrm{C}$ to remove cells, aliquoted to $0.4 \mathrm{~mL}$ samples in polypropylene tubes and stored at $-80^{\circ} \mathrm{C}$ until analysis. CSF biomarker levels of T-tau, P-Tau at threonine 181 and $\mathrm{A} \beta_{42}$ were measured in duplicate using the double sandwich ELISA method (Innogenetics) according to the manufacturer's instructions. We also calculated derived ratios from single biomarkers, including $\mathrm{T}-\operatorname{tau} / \mathrm{A} \beta_{42}$ and $\mathrm{P}-\mathrm{Tau} / \mathrm{A} \beta_{42}$.

Analyses for all patients, except for four, were performed in the Metabolic Biochemistry Department at the Pitié-Salpêtrière Hospital; analyses for the remaining four patients were performed at the Biological Neurochemistry laboratory at the University Hospital of Rennes. All operators were blind to clinical information. 
All biological and clinical data were generated during a routine clinical work-up and were retrospectively extracted for the purpose of this study. Therefore, according to French legislation, explicit informed consent was waived. However, regulations concerning electronic filing were followed, and patients and their relatives were informed that individual data might be used in retrospective clinical research studies.

\section{$\underline{\text { Statistical analysis }}$}

All statistical analyses were performed using Statview 4.0 (SAS Institute Inc., Version 5.0), MedCalc Software and STATISTICA 5.5A (@ StatSoft, Tulsa, Oklahoma, USA). Descriptive statistics were used to characterize each clinical group.

The samples were checked for normality by the Shapiro-Wilk test, which revealed that CSF biomarkers did not follow a normal distribution. The Mann-Whitney U-test was then employed to assess differences in demographics and biological data between the AD group and each of the other five clinical groups. The chi-square test was used to compare gender ratios. An alpha (significance) level of 0.05 was chosen.

Receiver operating characteristics (ROC) curve analyses were performed to evaluate the discriminating power of the different biomarkers and clinical diagnosis. The area under the curve (AUC) was used as a measure of the overall performance of each ROC curve (with a 95\% confidence interval). Moreover, we assessed whether the AUC values were significantly different using a nonparametric method for correlated samples (Delong's method). Finally, optimal cutoff points of biomarkers were calculated by selecting the point on the ROC curve that maximized both sensitivity and specificity.

The Spearman coefficient test was used to assess correlations between CSF variables, age, MMSE and disease duration. Bonferroni correction for multiple comparisons was applied. 
Because differences between the groups in CSF collection, CSF storage and center of recruitment were seen as potential sources of bias, we conducted further analyses that resulted in exclusion of the four patients who came from the Hospital of Rennes, all of whom were in the SD group. However, the results were not significantly modified after excluding these patients.

\section{RESULTS}

\section{Patient characteristics and mean CSF biomarker levels}

Demographic data, clinical data and CSF biomarker levels for each group of patients are shown in Table 1 (and table 4, as supplementary material on-line). There were no significant differences in age or mean disease duration between the AD group and each of the non-AD dementia groups (FTD, SD, PNFLA and PCA). Gender distribution was similar between the AD group and each of the non-AD dementia groups, except for PCA and PNFLA groups. No differences in the MMSE score were found between the AD group and non-AD dementia groups, except for SD patients who had slightly higher MMSE score than AD patients. Patients with FCD were younger than the AD patients and had a higher MMSE score. Gender distribution in FCD group was similar to the AD group.

The CSF $A \beta_{42}$ levels were significantly lower in the AD group compared with the FCD and SD groups, and the FTD levels were between the AD and SD group levels. No differences in CSF $A \beta_{42}$ levels were found among the AD, PCA and PNFLA groups $(\mathrm{AD}=\mathrm{PCA}=$ PNFLA $<\mathrm{FTD}<\mathrm{FCD})$.

The CSF T-tau and P-tau levels were significantly increased in the AD group compared with the FCD, FTD, SD and PNFLA groups $(\mathrm{AD}>$ PFNLA $>\mathrm{SD}=\mathrm{FTD}=\mathrm{FCD}$, for both biomarkers). This was especially true with the FCD, FTD and SD groups ( $p<0.0001$ for both markers). These differences, however, were less significant when compared with the PNFLA 
patients $(\mathrm{p}<0.01$ for Tau and $\mathrm{p}<0.05$ for P-Tau). There were no significant differences between the AD and PCA groups in T-tau levels.

The $\mathrm{T}-\operatorname{tau} / \mathrm{A} \beta_{42}$ and $\mathrm{P}-\mathrm{Tau} / \mathrm{A} \beta_{42}$ ratios were significantly higher in $\mathrm{AD}$ patients relative to FCD, FTD or SD patients ( $\mathrm{p}<0.0001$ for both ratios $)$. In addition, T-tau/A $\beta_{42}$ and PTau/A $\beta_{42}$ ratios were reduced in PNFLA and PCA patients relative to AD patients $(\mathrm{p}<0.01$ and $\mathrm{p}<0.05$, respectively; $\mathrm{AD}>\mathbf{P N F L A}=\mathrm{PCA}>\mathrm{FTD}=\mathrm{SD}>\mathrm{FCD})$.

$A \beta_{42}$ levels and the two ratios differed significantly between the FCD group and the FTD group. However, there were no differences in the CSF biomarker levels between the FTD and SD groups. All biomarker measures were significantly different in the PNFLA and PCA groups when compared with the FTD or SD groups.

No correlation was found between $\mathrm{A} \beta_{42}$ and T-tau or P-Tau levels for the entire population or within each group. A linear regression analysis between CSF T-tau and P-Tau levels showed a significant correlation for all groups studied (data not shown).

We also analyzed statistical correlation (Spearman test, with Bonferroni correction) between different CSF biomarkers and clinical data (age, disease duration or MMSE). The different CSF biomarkers and ratios $\left(\mathrm{A} \beta_{42}, \mathrm{~T}-\mathrm{tau}, \mathrm{P}-\mathrm{Tau}, \mathrm{T}-\mathrm{tau} / \mathrm{A} \beta_{42}\right.$ and P-Tau/A $\left.\beta_{42}\right)$ showed no significant correlations with age, gender, disease duration or MMSE for the entire population or within each group (the corrected $\mathrm{p}$ did reach significance level for none of the correlations).

\section{Determination of the sensitivity, specificity and optimal biomarker cutoff for differential}

\section{AD diagnosis}

A pairwise comparison of the area under the ROC curves revealed that T-tau/A $\beta_{42}$ and P-tau/A $\beta_{42}$ were better than each separated CSF biomarkers in discriminating AD patients from FCD, FTD, SD, PNFLA and PCA (see Figure 1). Based on the AUC, sensitivity and 
specificity, the P-tau/A $\beta_{42}$ ratio discriminated $\mathrm{AD}$ from $\mathrm{FCD}$ and others cortical dementias better than $\mathrm{A} \beta_{42}$, T-tau, P-tau and T-tau/A $\beta_{42}$.

Table 2 shows the sensitivity, specificity, AUC and optimal cutoffs determined by ROC analysis for discriminating the $\mathrm{AD}$ group from each clinical group.

The T-tau $/ \mathrm{A} \beta_{42}$ and the P-tau $/ \mathrm{A} \beta_{42}$ ratios better differentiated $\mathrm{AD}$ patients from SD or FTD patients than the individual CSF markers alone. The T-tau/A $\beta_{42}$ ratio discriminated AD from SD or FTD patients with a 95\% sensitivity (for both groups), and an $84.2 \%$ and $85.2 \%$ specificity, respectively. Similarly, the sensitivity for the $\mathrm{P}-\mathrm{tau} / \mathrm{A} \beta_{42}$ ratio for discriminating AD from FTD or SD was $91.7 \%$ and $98.3 \%$, respectively, whereas the specificity was $92.6 \%$ and $84.2 \%$, respectively (see Table 2). In contrast, CSF biomarkers and their ratios were less effective at discriminating AD from PNFLA and PCA patients.

Because we wanted to determine the optimal cutoff for a differential diagnosis of $\mathrm{AD}$, we grouped SD and FTD patients into an FTLD group. ROC curve analysis showed that sensitivity and specificity of P-tau /A $\beta_{42}$ ratio remained high ( $91 \%$ and $89 \%$, respectively). When the FCD and FTLD groups were pooled, we found a similar or higher sensitivity and specificity, except for the T-tau levels, as when the groups were considered alone. By comparing the FTLD group and FTLD pooled with FCD, the significant threshold for $A \beta_{42}$, $P$ tau, $T \operatorname{tau} / A \beta_{42}$ and $P \operatorname{tau} / A \beta_{42}$ did not change. The $T$ tau cut off was higher in the FTLD group than the FTLD group pooled with the FCD group.

\section{Individual biomarker profiles by diagnosis group}

To identify how CSF biomarkers can be included in the differential diagnosis of AD in clinical practice, we analyzed the percentages of patients by groups with altered levels of CSF biomarkers (Table 3). We chose the optimal cut-off determined by ROC analyses for 
discriminating FTLD and AD groups because of the known differences in underlying histopathological characteristics between the diseases.

As expected, $90 \%$ of $\mathrm{AD}$ patients had both abnormal T-tau/A $\beta_{42}$ and $\mathrm{P}-\operatorname{tau} / \mathrm{A} \beta_{42}$, whereas only one (3.7\%) FTD patient and three (15.8\%) SD patients had abnormal scores for both ratios. No FCD patients had abnormal scores for either CSF ratio. In contrast, at least $60 \%$ of PCA and PNFLA patients had both abnormal T-tau/A $\beta_{42}$ and P-tau/A $\beta_{42}$ ratios.

Figure 2 shows a scatterplot of CSF P-tau/A $\beta 42$ ratio in patients according to clinical diagnosis. A distinct distribution was observed between AD and FTD, SD and FCD patient data. By contrast, the distribution of P-tau/A $\beta 42$ ratio in $\mathrm{AD}$ patient data overlapped with PNFLA and PCA patient data.

\section{DISCUSSION}

We investigated the ability of CSF biomarkers to distinguish AD from other forms of neurodegenerative cortical dementia. The CSF biomarker levels in AD patients found here were similar to those typically observed in $\mathrm{AD}$ patients $[1,5]$. In analyzing the ability of CSF biomarkers to differentiate $\mathrm{AD}$ from non-AD dementias or $\mathrm{FCD}$, two main findings emerged. First, the combined CSF biomarker profiles measured by the T-Tau/A $\beta 42$ or P-Tau/A $\beta 42$ ratios were able to differentiate $\mathrm{AD}$ from $\mathrm{FTD}, \mathrm{SD}$ and $\mathrm{FCD}$ with very high sensitivity and specificity. These data indicate that FTD, SD and FCD were distinct from AD in their underlying biological causes. Conversely, CSF biomarkers were not able to differentiate AD from PCA and PNFLA with the same high accuracy, suggesting heterogeneity within the PCA and PNFLA patients and a possibility of AD pathology in some cases.

In agreement with previous studies [10,11,13-15], we found higher mean levels of CSF Tau and P-Tau and lower mean levels of CSF A $\beta 42$ in FTD patients, when compared to AD subjects. The P-Tau/A $\beta 42$ ratio appears to be the best biomarker profile for discriminating 
AD from FTD, with a sensitivity of $91.7 \%$, a specificity of $92.6 \%$ and very few false-positives (7\%). This finding is consistent with a previous study that reported a sensitivity of $77 \%$ and specificity of $81 \%$ for the P-Tau/A $\beta 42$ ratio in distinguishing AD from clinically-established FTLD (validated by two years of follow-up) [15]. Furthermore, a study with confirmed FTLD patients reported high sensitivity (79\%) and specificity (97\%) for the Tau/A $\beta 42$ ratio in distinguishing FTLD from AD [11]. In the latter study, combining neuropsychological measures with CSF biomarkers did not improve the ability to distinguish FTLD from AD, but no analyses were performed on the different variants of FTLD.

Semantic dementia is a rare cause of FTLD [31]. Memory complaints and forgetfulness of words, mimicking early $\mathrm{AD}$, are frequent reasons for consultation. Semantic dementia is frequently misdiagnosed as $\mathrm{AD}[18]$ because the speech in $\mathrm{SD}$ is fluent and not easily suggestive of progressive aphasia and also because semantic verbal deficits can disturb performance in tests of verbal episodic memory. Semantic dementia has different histopathological characteristics from $\mathrm{AD}[19,21]$. In pathologically-confirmed SD patients, FTLD with ubiquitin-positive, tau-negative inclusions and TAR-DNA-binding protein 43 (TDP-43) -positive inclusions were the most common finding [19, 21]. Surprisingly, a previous study of CSF biomarkers on SD ( $\mathrm{n}=13$ patients without autopsy) was not consistent with neuropathological data, showing similar CSF profiles to the AD group [14]. In our cohort, SD CSF profiles clearly differed from those of AD. The best biomarker pattern for discriminating SD from AD was the P-Tau/A $\beta 42$ ratio, which had high sensitivity $(98.3 \%)$ and specificity $(84.2 \%)$. The $\mathrm{P}-\mathrm{Tau} / \mathrm{A} \beta 42$ ratio appears to be able to differentiate the histopathological lesions associated with AD from those associated with FTD and SD.

The P-Tau/A $\beta 42$ ratio did not reach a similar power for discriminating AD from PNFLA and PCA, lacking sensitivity and specificity. This finding may be attributable to PPA not being a clinical entity with a homogeneous pathological profile, but corresponds to three 
possible phenotypes: SD, progressive non-fluent aphasia (PNFA) and logopenic aphasia

(see [20] for review). In an autopsy series, tau pathology was the main pathological diagnosis in PPA with speech apraxia [36, 37], classically called PNFA [20], while AD was the commonest cause of logopenic aphasia, which is characterized by non-fluent speech mimicking conduction aphasia [37]. These distinct clinical non-fluent PPA variants were also observed in an in-vivo study [22] that used positron tomography emission with the [11C]Pittsburgh compound B, a radioligand that was designed to measure the amount of fibrillar $\mathrm{A} \beta$ deposits [38] and that has been confirmed by a postmortem study in AD [39]. Our data, showing an overlap between CSF biomarkers levels between PNFLA and AD (see Figure 2), are in agreement with these neuropathological and PET studies.

Similarly, CSF P-Tau/A $\beta 42$ ratio does not discriminate PCA from AD with the same power that we observed in FTD, SD and FCD. Clinicopathological series found that AD was the most frequent cause of PCA, accounting for $80-100 \%$ of all cases $[18,35,40]$. An in vivo study of amyloid deposition by PET confirmed in a single patient that PCA is associated with amyloidosis [41].

Interestingly, individual data showed abnormal ratios for both T-tau/A $\beta 42$ and PTau/A $\beta 42$ in $61.5 \%$ of PNFLA patients and in $60 \%$ of PCA patients. A recent neuropathological study demonstrated that the combination of low A $\beta 42$ and high T-tau level in antemortem CSF predicted the presence of $\mathrm{AD}$-associated pathological changes with high accuracy and strongly supported the possibility of $\mathrm{AD}$ [42]. The P-tau/A $\beta 42$ ratio exhibited the best sensitivity and the highest specificity for patients with a confirmed AD diagnosis. Consistent with these data, patients with atypical cortical presentation of AD, such as PNFLA and PCA, could be identified by CSF biomarkers, particularly T-tau/A $\beta 42$ and P-Tau/A $\beta 42$ ratios. 
Combining CSF biomarkers may improve the in-vivo differential diagnosis between AD and both FTD and SD, which have distinct neuropathological causes. The combination of CSF biomarkers may also help to predict the underlying pathology in focal cortical presentations of AD (as in logopenic PPA and PCA) and to identify candidate patients for emerging therapies against amyloidosis.

While pathological data may be important for establishing diagnosis for the different groups of patients, no autopsy was available in our cohort. Future studies with autopsyconfirmed diagnoses are needed to confirm our findings, especially on the PNFLA group. It would also be of value to study the biomarker profile in a series of patients that were evaluated with positron tomography emission with the PIB, in order to test the concordance between CSF biomarkers and PIB data. It should be noted, however, that clinical diagnosis was established using accepted consensus criteria; all patients were extensively evaluated with clinical, biological, neuropsychological and neuroimaging exams. Furthermore, all patients had at least 18 months of clinical follow-up in centers with expertise in the field of dementias. Finally, all CSF data were obtained from the same center, except for four patients with SD, thus decreasing the risk of potential sources of bias in the biological results. 


\section{Acknowledgments}

We are thankful to Mrs. Floriane Chauvin, who helped in the collection of clinical and neuropsychological data for this study.

We thank Mrs. Carole Dufouil, for helping in statistical analysis.

We also thank Aurélie Funkiewiez, Dalila Samri, Elodie Guichart-Gomez, Valérie Hahn-Barma and Virginie Czernecki for performing the neuropsychological assessment of the patients in this work.

\section{Disclosures}

Dr. De Souza is founded by a grant from “Association France Alzheimer”.

Dr. Lamari, Dr. Houillier, Dr. De Paz and Dr. Jardel report no conflict of interest.

During the two last years, Dr Belliard has collaborated with the following pharmaceutical companies: EISAI and Lundbeck

During the two last years, Pr Dubois has collaborated with the following pharmaceutical companies: Eisai, Novartis, Roche, Bristol-Mayer-Squib, Servier.

During the two last years, Dr Sarazin has collaborated with the following pharmaceutical companies: EISAI and Novartis.

Competing Interest: None declared.

\section{Licence for Publication:}

The Corresponding Author has the right to grant on behalf of all authors and does grant on behalf of all authors, an exclusive licence (or non exclusive for government employees) on a worldwide basis to the BMJ Publishing Group Ltd to permit this article (if accepted) to be published in JNNP and any other BMJPGL products and sublicences such use and exploit all subsidiary rights, as set out in our licence. 


\section{REFERENCES}

1. Blennow K, Hampel H. CSF markers for incipient Alzheimer's disease. Lancet Neurol 2003;2(10):605-613.

2. Hulstaert F, Blennow K, Ivanoiu A, Schoonderwaldt HC, Riemenschneider M, De Deyn PP, et al. Improved discrimination of AD patients using beta-amyloid(1-42) and tau levels in CSF. Neurology 1999;52(8):1555-1562.

3. Ewers M, Buerger K, Teipel SJ, Scheltens P, Schroder J, Zinkowski RP, et al. Multicenter assessment of CSF-phosphorylated tau for the prediction of conversion of MCI. Neurology 2007;69(24):2205-2212.

4. Li G, Sokal I, Quinn JF, Leverenz JB, Brodey M, Schellenberg GD, et al. CSF tau/Abeta42 ratio for increased risk of mild cognitive impairment: a follow-up study. Neurology 2007;69(7):631-639.

5. Mattsson N, Zetterberg H, Hansson O, Andreasen N, Parnetti L, Jonsson M, et al. CSF biomarkers and incipient Alzheimer disease in patients with mild cognitive impairment. Jama 2009;302(4):385-393.

6. Brys M, Pirraglia E, Rich K, Rolstad S, Mosconi L, Switalski R, et al. Prediction and longitudinal study of CSF biomarkers in mild cognitive impairment. Neurobiol Aging 2009;30(5):682-690.

7. Visser PJ, Verhey F, Knol DL, Scheltens P, Wahlund LO, Freund-Levi Y, et al. Prevalence and prognostic value of CSF markers of Alzheimer's disease pathology in patients with subjective cognitive impairment or mild cognitive impairment in the DESCRIPA study: a prospective cohort study. Lancet Neurol 2009;8(7):619-627. 
8. Hansson O, Zetterberg H, Buchhave P, Londos E, Blennow K, Minthon L. Association between CSF biomarkers and incipient Alzheimer's disease in patients with mild cognitive impairment: a follow-up study. Lancet Neurol 2006;5(3):228-234.

9. Clark CM, Xie S, Chittams J, Ewbank D, Peskind E, Galasko D, et al. Cerebrospinal fluid tau and beta-amyloid: how well do these biomarkers reflect autopsy-confirmed dementia diagnoses? Arch Neurol 2003;60(12):1696-1702.

10. Riemenschneider M, Wagenpfeil S, Diehl J, Lautenschlager N, Theml T, Heldmann B, et al. Tau and Abeta42 protein in CSF of patients with frontotemporal degeneration. Neurology 2002;58(11):1622-1628.

11. Bian H, Van Swieten JC, Leight S, Massimo L, Wood E, Forman M, et al. CSF biomarkers in frontotemporal lobar degeneration with known pathology. Neurology 2008;70(19 Pt 2):1827-1835.

12. Paraskevas GP, Kapaki E, Liappas I, Theotoka I, Mamali I, Zournas C, et al. The diagnostic value of cerebrospinal fluid tau protein in dementing and nondementing neuropsychiatric disorders. J Geriatr Psychiatry Neurol 2005;18(3):163-173.

13. Koopman K, Le Bastard N, Martin JJ, Nagels G, De Deyn PP, Engelborghs S. Improved discrimination of autopsy-confirmed Alzheimer's disease (AD) from non-AD dementias using CSF P-tau(181P). Neurochem Int 2009;55(4):214-218.

14. Grossman M, Farmer J, Leight S, Work M, Moore P, Van Deerlin V, et al. Cerebrospinal fluid profile in frontotemporal dementia and Alzheimer's disease. Ann Neurol 2005;57(5):721-729.

15. Kapaki E, Paraskevas GP, Papageorgiou SG, Bonakis A, Kalfakis N, Zalonis I, et al. Diagnostic value of CSF biomarker profile in frontotemporal lobar degeneration. Alzheimer Dis Assoc Disord 2008;22(1):47-53. 
16. Buerger K, Zinkowski R, Teipel SJ, Tapiola T, Arai H, Blennow K, et al. Differential diagnosis of Alzheimer disease with cerebrospinal fluid levels of tau protein phosphorylated at threonine 231. Arch Neurol 2002;59(8):1267-1272.

\section{Schoonenboom NS, Pijnenburg YA, Mulder C, Rosso SM, Van Elk EJ, Van Kamp}

GJ, et al. Amyloid beta(1-42) and phosphorylated tau in CSF as markers for early-onset Alzheimer disease. Neurology 2004;62(9):1580-1584.

18. Alladi S, Xuereb J, Bak T, Nestor P, Knibb J, Patterson K, et al. Focal cortical presentations of Alzheimer's disease. Brain 2007;130(Pt 10):2636-2645.

19. Knibb JA, Xuereb JH, Patterson K, Hodges JR. Clinical and pathological characterization of progressive aphasia. Ann Neurol 2006;59(1):156-165.

20. Cummings J. Primary progressive aphasia and the growing role of biomarkers in neurological diagnosis. Ann Neurol 2008;64(4):361-364.

21. Snowden J, Neary D, Mann D. Frontotemporal lobar degeneration: clinical and pathological relationships. Acta Neuropathol 2007;114(1):31-38.

22. Rabinovici GD, Jagust WJ, Furst AJ, Ogar JM, Racine CA, Mormino EC, et al. Abeta amyloid and glucose metabolism in three variants of primary progressive aphasia. Ann Neurol 2008;64(4):388-401.

23. Folstein MF, Folstein SE, McHugh PR. "Mini-mental state". A practical method for grading the cognitive state of patients for the clinician. J Psychiatr Res 1975;12(3):189-198.

24. Grober E, Buschke H, Crystal H, Bang S, Dresner R. Screening for dementia by memory testing. Neurology 1988;38(6):900-903.

25. Dubois B, Slachevsky A, Litvan I, Pillon B. The FAB: a Frontal Assessment Battery at bedside. Neurology 2000;55(11):1621-1626. 
26. Kremin H PD, De Wilde M. DENO-100-Paradigme expérimental et test clinique de dénomination contrôlée: effet relatif de 7 variables expérimentales sur les performances de 16 sujets atteints de maladies dégénératives. Rev Neuropsychol 1999;9:439-440.

27. McKhann G, Drachman D, Folstein M, Katzman R, Price D, Stadlan EM. Clinical diagnosis of Alzheimer's disease: report of the NINCDS-ADRDA Work Group under the auspices of Department of Health and Human Services Task Force on Alzheimer's Disease. Neurology 1984;34(7):939-944.

28. Neary D, Snowden JS, Gustafson L, Passant U, Stuss D, Black S, et al. Frontotemporal lobar degeneration: a consensus on clinical diagnostic criteria. Neurology 1998;51(6):1546-1554.

29. McKhann GM, Albert MS, Grossman M, Miller B, Dickson D, Trojanowski JQ.

Clinical and pathological diagnosis of frontotemporal dementia: report of the Work Group on Frontotemporal Dementia and Pick's Disease. Arch Neurol 2001;58(11):1803-1809.

30. Adlam AL, Patterson K, Rogers TT, Nestor PJ, Salmond CH, Acosta-Cabronero J, et al. Semantic dementia and fluent primary progressive aphasia: two sides of the same coin? Brain 2006;129(Pt 11):3066-3080.

31. Moreaud O, Belliard S, Snowden J, Auriacombe S, Basaglia-Pappas S, Bernard F, et al. [Semantic dementia: reflexions of a French working group for diagnostic criteria and constitution of a patient cohort]. Rev Neurol (Paris) 2008;164(4):343-353.

32. Mesulam MM, Grossman M, Hillis A, Kertesz A, Weintraub S. The core and halo of primary progressive aphasia and semantic dementia. Ann Neurol 2003;54 Suppl 5:S11-14.

33. Gorno-Tempini ML, Brambati SM, Ginex V, Ogar J, Dronkers NF, Marcone A, et al. The logopenic/phonological variant of primary progressive aphasia. Neurology 2008;71(16):1227-1234. 
34. Mendez MF, Ghajarania M, Perryman KM. Posterior cortical atrophy: clinical characteristics and differences compared to Alzheimer's disease. Dement Geriatr Cogn Disord 2002;14(1):33-40.

35. Tang-Wai DF, Graff-Radford NR, Boeve BF, Dickson DW, Parisi JE, Crook R, et al. Clinical, genetic, and neuropathologic characteristics of posterior cortical atrophy. Neurology 2004;63(7):1168-1174.

36. Mesulam M, Wicklund A, Johnson N, Rogalski E, Leger GC, Rademaker A, et al. Alzheimer and frontotemporal pathology in subsets of primary progressive aphasia. Ann Neurol 2008;63(6):709-719.

37. Deramecourt V, Lebert F, Debachy B, Mackowiak-Cordoliani MA, Bombois S, Kerdraon O, et al. Prediction of pathology in primary progressive language and speech disorders. Neurology;74(1):42-49.

38. Tolboom N, van der Flier WM, Yaqub M, Boellaard R, Verwey NA, Blankenstein MA, et al. Relationship of cerebrospinal fluid markers to 11C-PiB and 18F-FDDNP binding. J Nucl Med 2009;50(9):1464-1470.

39. Ikonomovic MD, Klunk WE, Abrahamson EE, Mathis CA, Price JC, Tsopelas ND, et al. Post-mortem correlates of in vivo PiB-PET amyloid imaging in a typical case of Alzheimer's disease. Brain 2008;131(Pt 6):1630-1645.

40. Renner JA, Burns JM, Hou CE, McKeel DW, Jr., Storandt M, Morris JC. Progressive posterior cortical dysfunction: a clinicopathologic series. Neurology 2004;63(7):1175-1180.

41. Ng SY, Villemagne VL, Masters CL, Rowe CC. Evaluating atypical dementia syndromes using positron emission tomography with carbon 11 labeled Pittsburgh Compound B. Arch Neurol 2007;64(8):1140-1144. 
42. Tapiola T, Alafuzoff I, Herukka SK, Parkkinen L, Hartikainen P, Soininen H, et al.

Cerebrospinal fluid \{beta $\}$-amyloid 42 and tau proteins as biomarkers of Alzheimer-type pathologic changes in the brain. Arch Neurol 2009;66(3):382-389. 
Table 1: Demographic and CSF data of studied groups.

\begin{tabular}{|c|c|c|c|c|c|c|}
\hline & AD & FTD & SD & FCD & PCA & PNFLA \\
\hline $\mathbf{N}$ & 60 & 27 & 19 & 17 & 15 & 26 \\
\hline Age & $63.6(57-72)$ & $66(59-73)$ & $60(57-68)$ & $56(52-58)^{b}$ & $62(57-67)$ & $65.5(62-71)$ \\
\hline Sex ratio $(M / F)$ & $30 / 30$ & $15 / 12$ & $9 / 10$ & $12 / 9$ & $3 / 12$ & $10 / 16$ \\
\hline Disease duration (years) & $3(2-4)$ & $3(2-5)$ & $4(2-7)$ & Not applicated & $3(2-5)$ & $4(3-5)$ \\
\hline MMSE & $20(17-24)$ & $21(18-23)$ & $22(21-27)^{\mathbf{c}}$ & $27(26-28)^{\text {ad }}$ & $19(16-22)$ & $21(20-24)$ \\
\hline FAB & $13(11-14)$ & $13(6-14)$ & $15(12-17)$ & $15(13-17)^{a}$ & $9(6-14)$ & $14(10-17)$ \\
\hline Aß42 (ng/ml) & $237.6(155.5-315.5)$ & $394(306.2-473)^{\mathbf{a}}$ & $532(308.2-682.2)^{\mathrm{a}}$ & $500(417-614.5)^{\text {ad }}$ & $241(227.2-382.7)^{\mathrm{NSd}}$ & $263.5(206-351)^{\mathrm{NSd}}$ \\
\hline T-tau (ng/ml) & $571(419-796.5)$ & $239(137-407.4)^{a}$ & $317(209.5-433.7)^{\mathrm{a}}$ & $185(141.2-262.7)^{\mathrm{a}}$ & $436(368.3-496.5)^{\mathrm{NS} \mathrm{d}}$ & $414(288-556)^{\mathbf{b d}}$ \\
\hline P-tau (ng/ml) & $84.2(69-107.5)$ & $43.5(32.5-57)^{\mathrm{a}}$ & $46.2(38.4-67.0)^{\mathrm{a}}$ & $34(30.2-56.9)^{\mathrm{a}}$ & $58(47.3-77.7)^{\mathbf{c d}}$ & $59.95(49-86)^{\mathrm{cd}}$ \\
\hline T-tau/A $\beta 42$ & $2.450(1.688-3.433)$ & $0.582(0.396-1.055)^{\mathrm{a}}$ & $0.492(0.35-0.928)^{\mathbf{a}}$ & $0.335(0.31-0.51)^{\text {ad }}$ & $1.759(1.13-2.46)^{\mathrm{cd}}$ & $1.528(0.85-2.31)^{\mathrm{cd}}$ \\
\hline P-tau/A $\beta 42$ & $0.43(0.26-0.48)$ & $0.13(0.08-0.15)^{\mathrm{a}}$ & $0.18(0.06-0.13)^{\mathrm{a}}$ & $0.074(0.066-0.093)^{\mathrm{ad}}$ & $0.26(0.14-0.31)^{b d}$ & $0.30(0.16-0.39)^{\mathbf{b d}}$ \\
\hline
\end{tabular}




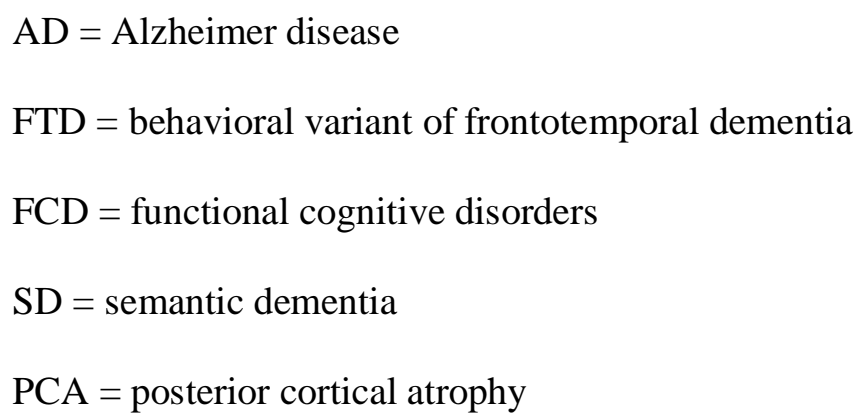

Comparison between AD patients and other groups was performed using a non-parametric Mann-Whitney U-test with the following annotations: NS Non significant vs AD group
a $\mathrm{p}<0.0001$
b $\mathrm{p}<0.01$
c $\mathrm{p}<0.05$
$\mathrm{d} p<0.05$ Mann-Whitney U-Test vs. FTD group

Please access supplemental material on-line (table 4) to find this data presented in mean and standard deviation (SD) values 
Table 2: Results of ROC analyses for discrimination of AD from other clinical diagnoses.

Values in parentheses indicate $95 \%$ confidence interval

* Significance of discrimination ( $\mathrm{P}$ value for significant difference in area under the ROC curve $=0.5$ ) 


\begin{tabular}{|c|c|c|c|c|c|}
\hline & Cutoff (pg/mL) & Sensitivity (\%) & Specificity (\%) & AUC & $\mathbf{p}$ \\
\hline \multicolumn{6}{|l|}{ AD vs FCD } \\
\hline $\mathrm{A} \beta_{42}$ & 395 & 93.3 & 82.4 & $0.940(0.862$ to 0.981$)$ & 0.0001 \\
\hline T-Tau & 289 & 90 & 94.1 & $0.931(0.849$ to 0.976$)$ & 0.0001 \\
\hline P-Tau & 64 & 83.3 & 94.1 & $0.900(0.811$ to 0.957$)$ & 0.0001 \\
\hline $\mathrm{Tau} / \mathrm{A} \beta_{42}$ & 0.77 & 98.3 & 100 & $0.988(0.930-1.00)$ & 0.0001 \\
\hline $\mathrm{P}-\mathrm{Tau} / \mathrm{A} \beta_{42}$ & 0.140 & 98.3 & 100 & $0.984(0.925-0.99)$ & 0.0001 \\
\hline \multicolumn{6}{|l|}{ AD vs FTD } \\
\hline $\mathrm{A} \beta_{42}$ & 292.1 & 68.3 & 85.2 & $0.817(0.720-0.892)$ & 0.0001 \\
\hline T-Tau & 458 & 70 & 88.9 & $0.832(0.736-0.903)$ & 0.0001 \\
\hline P-Tau & 62.5 & 83.3 & 85.2 & $0.851(0.759-0.918)$ & 0.0001 \\
\hline $\mathrm{Tau} / \mathrm{A} \beta_{42}$ & 1.23 & 95 & 85.2 & $0.926(0.849-0.971)$ & 0.0001 \\
\hline P-Tau/A $\beta_{42}$ & 0.211 & 91.7 & 92.6 & $0.942(0.871-0.981)$ & 0.0001 \\
\hline \multicolumn{6}{|l|}{ AD vs SD } \\
\hline $\mathrm{A} \beta_{42}$ & 425 & 98.3 & 68.4 & $0.810(0.706-0.889)$ & 0.0001 \\
\hline T-Tau & 493 & 65 & 89.5 & $0.813(0.709-0.892)$ & 0.0001 \\
\hline P-Tau & 74 & 63.3 & 94.7 & $0.825(0.723-0.901)$ & 0.0001 \\
\hline $\mathrm{Tau} / \mathrm{A} \beta_{42}$ & 1.05 & 95 & 84.2 & $0.876(0.783-0.940)$ & 0.0001 \\
\hline P-Tau/A $\beta_{42}$ & 0.143 & 98.3 & 84.2 & $0.864(0.768-0.931)$ & 0.0001 \\
\hline \multicolumn{6}{|l|}{ AD vs PNFLA } \\
\hline $\mathrm{A} \beta_{42}$ & 234 & 50 & 69.2 & $0.581(0.470-0.687)$ & 0.2346 \\
\hline T-Tau & 616 & 46.7 & 88.5 & $0.686(0.576-0.781)$ & 0.0017 \\
\hline P-Tau & 62 & 85 & 53.8 & $0.671(0.562-0.769)$ & 0.0044 \\
\hline $\mathrm{Tau} / \mathrm{A} \beta_{42}$ & 1.678 & 75 & 65.4 & $0.713(0.606-0.806)$ & 0.0002 \\
\hline P-Tau/A $\beta_{42}$ & 0.296 & 68.3 & 69.2 & $0.688(0.579-0.783)$ & 0.0014 \\
\hline AD vs PCA & & & & & \\
\hline
\end{tabular}




\begin{tabular}{|c|c|c|c|c|c|}
\hline $\mathrm{A} \beta_{42}$ & 221 & 41.7 & 86.7 & $0.614(0.494-0.724)$ & 0.1796 \\
\hline T-Tau & 497 & 63.3 & 80 & $0.663(0.545-0.768)$ & 0.0251 \\
\hline P-Tau & 59.5 & 86.7 & 60 & $0.705(0.588-0.805)$ & 0.0027 \\
\hline $\mathrm{Tau} / \mathrm{A} \beta_{42}$ & 1.33 & 88.3 & 46.7 & $0.706(0.589-0.805)$ & 0.0026 \\
\hline P-Tau/A $\beta_{42}$ & 0.311 & 61.7 & 80 & $0.733(0.618-0.828)$ & 0.0003 \\
\hline \multicolumn{6}{|l|}{ AD vs SD + FTD } \\
\hline $\mathrm{A} \beta_{42}$ & 379 & 91.7 & 60.9 & $0.814(0.727-0.883)$ & 0.0001 \\
\hline T-Tau & 465 & 68.3 & 87 & $0.824(0.738-0.891)$ & 0.0001 \\
\hline P-Tau & 64 & 83.3 & 80.4 & $0.840(0.757-0.904)$ & 0.0001 \\
\hline $\mathrm{Tau} / \mathrm{A} \beta_{42}$ & 1.23 & 95 & 84.8 & $0.905(0.833-0.954)$ & 0.0001 \\
\hline P-Tau/A $\beta_{42}$ & 0.211 & 91.7 & 89.1 & $0.911(0.839-0.957)$ & 0.0001 \\
\hline \multicolumn{6}{|c|}{ AD vs SD + FTD + FCD } \\
\hline $\mathrm{A} \beta_{42}$ & 379 & 91.7 & 66.7 & $0.848(0.772-0.906)$ & 0.0001 \\
\hline T-Tau & 341 & 88.3 & 73 & $0.853(0.778-0.910)$ & 0.0001 \\
\hline P-Tau & 64 & 83.3 & 84.1 & $0.857(0.782-0.913)$ & 0.0001 \\
\hline $\mathrm{Tau} / \mathrm{A} \beta_{42}$ & 1.23 & 95 & 88.9 & $0.928(0.866-0.966)$ & 0.0001 \\
\hline $\mathrm{P}-\mathrm{Tau} / \mathrm{A} \beta_{42}$ & 0.211 & 91.7 & 92.1 & $0.930(0.870-0.968)$ & 0.0001 \\
\hline
\end{tabular}


Table 3: Number of patients (\%) with altered values of individual CSF biomarkers and their ratios, with patients divided into the studied groups.

The employed cut-offs were those found from ROC curves for discriminating AD from FTD pooled with SD.

\begin{tabular}{|c|c|c|c|c|c|c|}
\hline & AD & FCD & FTD & SD & PCA & PNFLA \\
\hline $\mathrm{A} \beta 42<379 \mathrm{pg} / \mathrm{ml}$ & $55 / 60(91.6)$ & $3 / 17(17.64)$ & $12 / 27(44)$ & $6 / 19(31.5)$ & $11 / 15(73)$ & $21 / 26(80.7)$ \\
\hline T-tau $>465 \mathrm{pg} / \mathrm{ml}$ & $41 / 60(68.3)$ & $2 / 17(11.76)$ & $3 / 27(11.1)$ & $4 / 19(21.05)$ & $6 / 15(40)$ & $10 / 26(38.46)$ \\
\hline P-Tau $>64.3 \mathrm{pg} / \mathrm{ml}$ & $50 / 60(83.3)$ & $1 / 17(5.88)$ & $4 / 27(14.81)$ & $5 / 19(26)$ & $6 / 15(40)$ & $12 / 26(46.1)$ \\
\hline $\mathrm{T}-\operatorname{tau} / \mathrm{A} \beta 42>1.23$ & $57 / 60(95)$ & $0 / 17$ & $4 / 27(14.81)$ & $3 / 19(15.8)$ & $11 / 15(73)$ & $17 / 26(65.3)$ \\
\hline $\mathrm{P}-\operatorname{tau} / \mathrm{A} \beta 42>0.211$ & $54 / 60(90)$ & $0 / 17$ & $2 / 27(7.4)$ & $3 / 19(15.8)$ & $9 / 15(60)$ & $16 / 26(61.5)$ \\
\hline T-tau/A $\beta 42>1.23$ and P-tau/A $\beta 42>0.211$ & $54 / 60(90)$ & $0 / 17$ & $1 / 27(3.7)$ & $3 / 19(15.8)$ & $9 / 15(60)$ & $16 / 26(61.5)$ \\
\hline
\end{tabular}


Figure 1: ROC curves of the sensitivity and specificity for individual CSF biomarkers and ratios in discriminating AD patients from PCA (A), FTD (B), SD (C) and PNFLA (D) patients. The combination of the two ratios (T-tau/A $\beta 42>1.23$ and P-tau/A $\beta 42>0.211)$ discriminated AD patients from PCA (A), FTD (B), SD (C) and PNFLA (D) patients with 95\% sensitivity and $94 \%$ specificity, with a positive predictive value of $93 \%$ and a negative predictive value of $95.4 \%$. 
Figure 2: Scatterplot of CSF P-tau/A $\beta_{42}$ ratio in patients according to clinical diagnosis.

Figure $2 \mathrm{a}$ shows distinct distribution of these scores between $\mathrm{AD}$ patients and FTD, SD and FCD patients. Figure $2 b$ shows greater overlap in the distribution of $P$-tau/ $A \beta_{42}$ ratio in $A D$, PNFLA and PCA patients. 


\section{Appendices: Supplemental material on-line}

Table 4: Demographic and CSF data of studied groups. Data are presented as mean ( \pm SD, maximum - minimum) for each variable.

$\mathrm{AD}=$ Alzheimer disease

FTD = behavioral variant of frontotemporal dementia

FCD $=$ functional cognitive disorders

$\mathrm{SD}=$ semantic dementia

PCA = posterior cortical atrophy

\section{PNFLA = progressive non fluent or logopenic aphasia}

MMSE $=$ Mini-Mental State Exam

$\mathrm{FAB}=$ Frontal Assessment Battery

Comparison between AD patients and other groups was performed using a non-parametric Mann-Whitney U-test with the following annotations:

NS Non significant
a $\mathrm{p}<0.0001$
b $\mathrm{p}<0.01$
c $\mathrm{p}<0.05$
$\mathrm{d} p<0.05$ Mann-Whitney U-Test vs. FTD group 


\begin{tabular}{|c|c|c|c|c|c|c|}
\hline & AD & FTD & SD & FCD & PCA & PNFLA \\
\hline $\mathbf{N}$ & 60 & 27 & 19 & 17 & 15 & 26 \\
\hline Age & $\begin{array}{l}64.3 \pm 9.8 \\
(48-85)\end{array}$ & $\begin{array}{c}63.11 \pm 11.2 \\
(24-86)\end{array}$ & $\begin{array}{c}61.41 \pm 7.45 \\
(50-76)\end{array}$ & $\begin{array}{l}57 \pm 10^{b d} \\
(44-85)\end{array}$ & $\begin{array}{l}71 \pm 5.66 \\
(67-75)\end{array}$ & $\begin{array}{l}66 \pm 7.45 \\
(46-82)\end{array}$ \\
\hline Sex ratio $M / F$ & $29 \mathrm{M} / 32 \mathrm{~F}$ & $13 \mathrm{M} / 14 \mathrm{~F}$ & $9 \mathrm{M} / 8 \mathrm{~F}$ & $12 \mathrm{M} / 9 \mathrm{~F}$ & $3 \mathrm{M} / 12 \mathrm{~F}$ & $12 \mathrm{M} / 14 \mathrm{~F}$ \\
\hline $\begin{array}{c}\text { Disease duration } \\
\text { (years) }\end{array}$ & $\begin{array}{l}4 \pm 2.48 \\
(1-14)\end{array}$ & $\begin{array}{c}4.22 \pm 3.33 \\
(1-14)\end{array}$ & $\begin{array}{c}4.27 \pm 3.21 \\
(1-11)\end{array}$ & Not applicated & $\begin{array}{c}3.42 \pm 1.87 \\
(2-8)\end{array}$ & $\begin{array}{l}4 \pm 2.39 \\
(1-10)\end{array}$ \\
\hline MMSE & $\begin{array}{c}20 \pm 5.41 \\
(6-29)\end{array}$ & $\begin{array}{l}20 \pm 4.62 \\
(10-27)\end{array}$ & $\begin{array}{l}22 \pm 6^{\mathrm{c}} \\
(7-30)\end{array}$ & $\begin{array}{c}27 \pm 1.94^{\text {ad }} \\
(24-30)\end{array}$ & $\begin{array}{c}19 \pm 5.19 \\
(6-26)\end{array}$ & $\begin{array}{l}22 \pm 4.27 \\
(13-30)\end{array}$ \\
\hline FAB & $\begin{array}{c}11 \pm 3.84 \\
(0-17)\end{array}$ & $\begin{array}{c}10 \pm 4.72 \\
(1-15)\end{array}$ & $\begin{array}{c}13.5 \pm 2.77 \\
(10-17)\end{array}$ & $\begin{array}{c}15 \pm 2.7^{a} \\
(9-18)\end{array}$ & $\begin{array}{c}9.14 \pm 4.47 \\
(0-16)\end{array}$ & $\begin{array}{c}13 \pm 3.81 \\
(6-18)\end{array}$ \\
\hline $\mathbf{A} \boldsymbol{\beta} 42$ & $\begin{array}{c}244.23 \pm 95.31 \\
(62-460)\end{array}$ & $\begin{array}{c}408.36 \pm 149.80^{a} \\
(187-817)\end{array}$ & $\begin{array}{c}563.94 \pm 404.73^{b} \\
(62-1711)\end{array}$ & $\begin{array}{c}530.7 \pm 168.96^{\text {ad }} \\
(286-900)\end{array}$ & $\begin{array}{c}288.42 \pm 99.49^{\mathrm{NSd}} \\
(129-456)\end{array}$ & $\begin{array}{c}315.44 \pm 174.27^{\mathrm{NSd}} \\
(120-786)\end{array}$ \\
\hline T-tau & $\begin{array}{l}554 \pm 306.85 \\
(131-1763)\end{array}$ & $\begin{array}{c}312 \pm 217.72^{a} \\
(84-906)\end{array}$ & $\begin{array}{c}354.47 \pm 256.56^{\mathbf{b}} \\
(74-1190)\end{array}$ & $\begin{array}{c}207.65 \pm 107.67^{\mathrm{a}} \\
(70-529)\end{array}$ & $\begin{array}{c}502.36 \pm 243.0^{\mathrm{NS} d} \\
(168-1110)\end{array}$ & $\begin{array}{c}477 \pm 317.93^{\mathrm{cd}} \\
(127-1300)\end{array}$ \\
\hline P-tau & $\begin{array}{l}84 \pm 38.69 \\
(15-212)\end{array}$ & $\begin{array}{c}48.4 \pm 22.92^{a} \\
(12-106)\end{array}$ & $\begin{array}{c}54.28 \pm 34.40^{\mathrm{a}} \\
(12-163)\end{array}$ & $\begin{array}{c}41.67 \pm 18.62^{\text {add }} \\
(17-83)\end{array}$ & $\begin{array}{c}68.15 \pm 33.48^{\mathbf{c d}} \\
(27-143)\end{array}$ & $\begin{array}{c}73 \pm 39.45^{\text {cd }} \\
(34-178)\end{array}$ \\
\hline T-tau/A $\beta 42$ & $\begin{array}{l}2.41 \pm 1.67 \\
(0.31-8.59)\end{array}$ & $\begin{array}{l}0.582 \pm 0.72^{a} \\
(0.25-3.69)\end{array}$ & $\begin{array}{l}1.12 \pm 1.47^{\mathrm{a}} \\
(0.26-5.5)\end{array}$ & $\begin{array}{l}0.39 \pm 0.15^{\text {ad }} \\
(0.13-0.77)\end{array}$ & $\begin{array}{l}1.92 \pm 1.12^{\mathrm{cd}} \\
(0.69-4.99)\end{array}$ & $\begin{array}{l}1.84 \pm 1.35^{\mathbf{b d}} \\
(0.23-5.83)\end{array}$ \\
\hline P-Tau/A $\beta 42$ & $\begin{array}{c}0.362 \pm 0.22 \\
(0.035-1.255)\end{array}$ & $\begin{array}{l}0.10 \pm 0.09^{\mathrm{a}} \\
(0.04-0.51)\end{array}$ & $\begin{array}{l}0.18 \pm 0.26^{\mathrm{a}} \\
(0.03-1.03)\end{array}$ & $\begin{array}{l}0.08 \pm 0.027^{\mathrm{a}} \\
(0.03-0.14)\end{array}$ & $\begin{array}{l}0.26 \pm 0.15^{\mathbf{b d}} \\
(0.05-0.64)\end{array}$ & $\begin{array}{l}0.29 \pm 0.20^{\mathbf{b d}} \\
(0.04-0.86)\end{array}$ \\
\hline
\end{tabular}



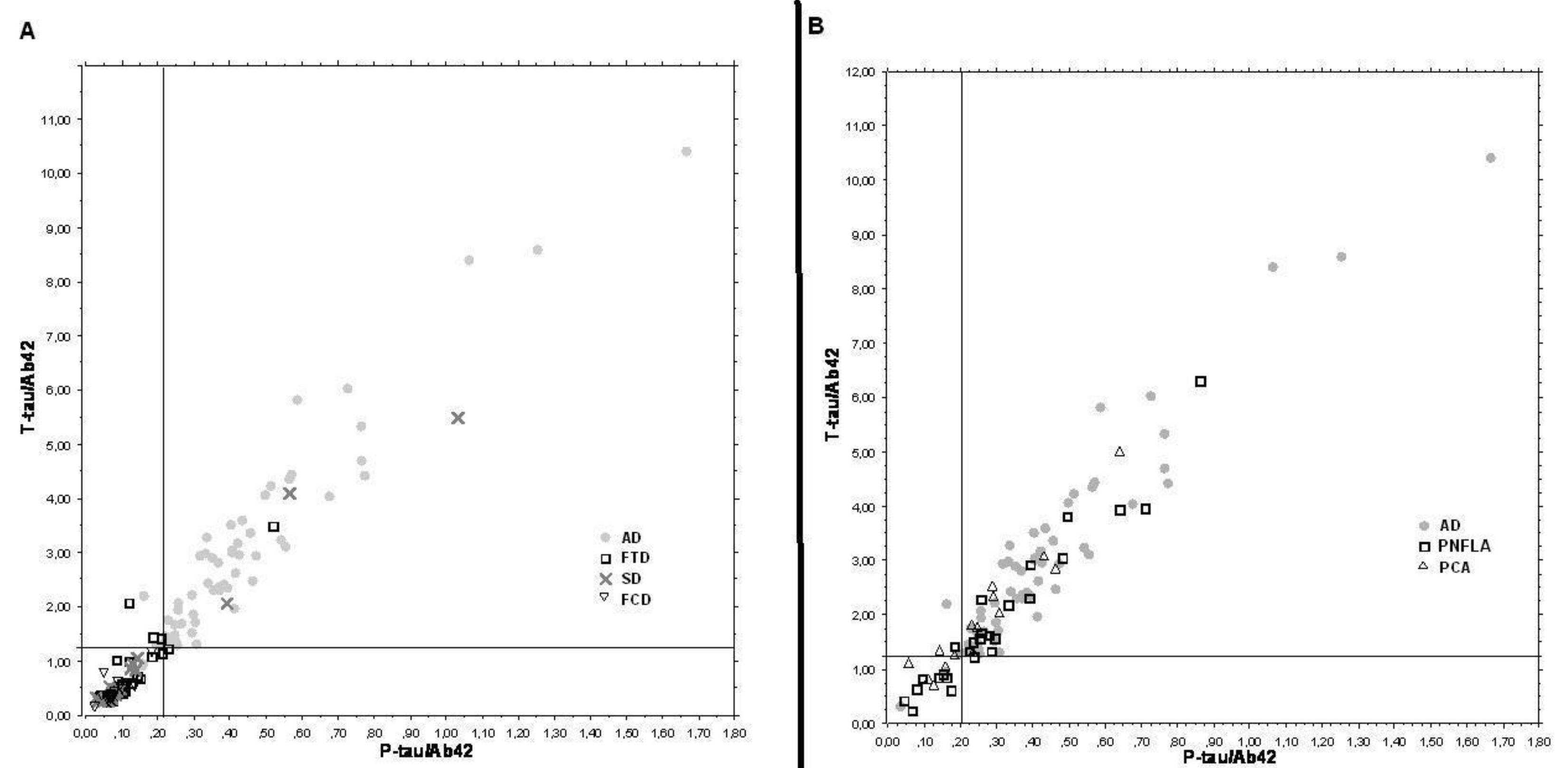